\title{
UV Assay Method for the Determination of Doxycycline Hyclate in Bulk and Pharmaceutical Formulation
}

\author{
V. SREERAM ${ }^{*}$, A. V. D. NAGENDRAKUMAR ${ }^{1}$, \\ SRINIVASA RAO KARUMURI ${ }^{2}$ and M. MADHU ${ }^{3}$
}

*P.G. Department of Chemistry, A.G \& S.G. Siddhartha College of Arts \& Science, Vuyyuru-521 165, India

${ }^{1}$ Department of Chemistry, GITAM University, Visakhapatnam-530 045, Andhra Pradesh, India

${ }^{2}$ Department of Electronics \& Instrumentation,

Lakireddy Bali Reddy College of Engineering, Mylavaram, A.P, India

${ }^{3}$ Department of Chemistry, P.B. Siddhartha College of Arts \& Science,

Vijayawada, A.P. India

sreeram_venigalla@yahoo.co.in

Received 5 July 2014 / Accepted 26 July 2014

\begin{abstract}
A simple, selective, linear, precise and accurate UV Assay method was developed and validated for rapid assay of Doxycycline hyclate in bulk and pharmaceutical formulation. For this development paddle apparatus were used. The purified water was used as dissolution medium and solvent. Stirring rate was employed at $75 \mathrm{rpm}$ and the withdrawal time was identified as 30 minutes and the filter size was found to be $0.45 \mu \mathrm{m}$ at ambient temperature. The method was validated as per the ICH guidelines. The method was successfully applied for routine analysis of Doxycycline hyclate in the rapid and reliable determination in pharmaceutical formulation.
\end{abstract}

Keywords: Doxycycline hyclate, RP-HPLC, UV detection, Recovery

\section{Introduction}

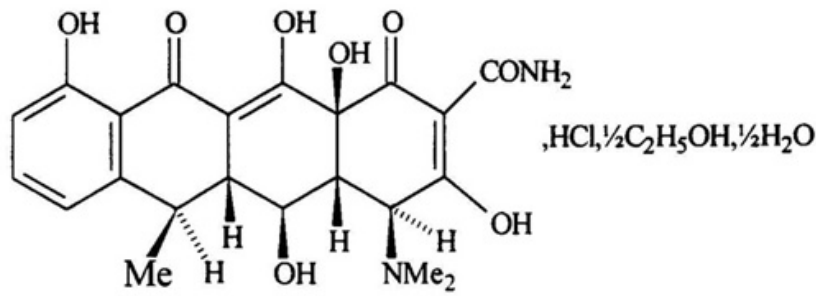

Figure 1. Structure of Doxycycline hyclate 
The molecular formulae of Doxycycline hyclate is $\mathrm{C}_{22} \mathrm{H}_{24} \mathrm{~N}_{2} \mathrm{O}_{8}, \mathrm{HCl}, 1 / 2 \mathrm{C}_{2} \mathrm{H}_{6} \mathrm{O}, 1 / 2 \mathrm{H}_{2} \mathrm{O}$. The systematic IUPAC name is Hydrochloride hemiethanol hemihydrate of (4S,4aR,5S,5aR,6R, 12aS)-4- (dimethylamino)-3,5,10,12,12a-pentahydroxy-6-methyl1,11-dioxo-1,4,4a,5,5a,6,11, 12a-octahydrotetracene-2-carboxamide (DOX). In addition to the general indications for all members of the tetracycline antibiotics group, Doxycycline is frequently used to treat Lyme disease, chronic prostatitis, sinusitis, pelvic inflammatory disease ${ }^{1,2}$, acne, rosacea ${ }^{3,4}$ and rickettsial infections ${ }^{5}$. According to Snežana et al. ${ }^{6}$ developed that the drug and the standard were eluted from a Lichrosorb RP-8 $(250 \mathrm{~mm} \times 4.6 \mathrm{~mm}, 10 \mu \mathrm{m}$ particle size $)$ at $20{ }^{\circ} \mathrm{C}$ with a mobile phase consisting of methanol, acetonitrile and $0.010 \mathrm{M}$ aqueous solution of oxalic acid $(2: 3: 5, \mathrm{v} / \mathrm{v} / \mathrm{v})$. The flow rate was $1.25 \mathrm{~mL} \mathrm{~min}^{-1}$. A UV detector set at $350 \mathrm{~nm}$ was used to monitor the effluent. Each analysis required no longer than $4 \mathrm{~min}$. The limits of detection and quantification were 1.15 and $3.84 \mu \mathrm{g} \mathrm{mL} \mathrm{m}^{-1}$, respectively. Recoveries for different concentrations ranged from 99.58 to $101.93 \%$ Ramesh et.al., ${ }^{7}$ described three simple, selective, rapid, accurate, precise and cost-effective spectrophotometric methods for the determination of DOX in bulk drug and in tablets. First method (method A) is based on the measurement of absorbance of DOX in $0.1 \mathrm{M} \mathrm{HCl}$ at $240 \mathrm{~nm}$. The second method (method B) is based on the measurement of yellow chromogen at $375 \mathrm{~nm}$ which is formed in $0.1 \mathrm{M} \mathrm{NaOH}$. The third method is based on the measurement of 2: 1 complex formed between DOX and iron(III) in HSO medium, the complex peaking at $420 \mathrm{~nm}$ (method $\mathrm{C})$. The optimum conditions for all the three methods are optimized. Beer's law was obeyed over the ranges 2.5-50.0, 1.50-30.0 and 10-100 g/mL for method A, method $\mathrm{B}$ and method $\mathrm{C}$, respectively. The apparent molar absorptivity values were calculated to be $1.03 \tilde{\mathrm{A}}-10,1.73 \tilde{\mathrm{A}}-10$, and $5.21 \tilde{\mathrm{A}}-10 \mathrm{~L}$ mol $\mathrm{cm}$ for method A, method B and method $\mathrm{C}$, respectively. Pavagada et.al., ${ }^{8}$ has been developed that the best separation was achieved on a $250 \mathrm{~mm} \times 4.0 \mathrm{~mm}$ i.d, $5.0 \mu \mathrm{m}$ particle size C 8 reversed phase thermo column with acetonitrile-potassium dihydrogenorthophosphate buffer $(\mathrm{pH}$ 4.0), 40:60 (v/v) as mobile phase at a flow rate of $1.0 \mathrm{~mL} / \mathrm{min}$. UV detection was performed at $325 \mathrm{~nm}$ at ambient column temperature $\left(25^{\circ} \mathrm{C}\right)$. The method was linear over the concentration range of $30-300 \mu \mathrm{g} / \mathrm{mL}(\mathrm{r}=0.9994)$ with limits of detection and quantification of 0.02 and $0.1 \mu \mathrm{g} / \mathrm{mL}$, respectively. Ghada et al., ${ }^{9}$ described a HPLC and multivariate spectrophotometric methods were described for the simultaneous determination of ambroxol hydrochloride (AM) and Doxycycline (DOX) in combined pharmaceutical capsules. The chromatographic separation was achieved on reversedphase $\mathrm{C}_{18}$ analytical column with a mobile phase consisting of a mixture of $20 \mathrm{mM}$ potassium dihydrogen phosphate, $\mathrm{pH}$ 6-acetonitrile in ratio of $(1: 1, \mathrm{v} / \mathrm{v})$ and $\mathrm{UV}$ detection at $245 \mathrm{~nm}$. Slavica et al., ${ }^{10}$ has developed that the separation of Doxycycline was achieved at $40{ }^{\circ} \mathrm{C}$ on a reversed-phase $\mathrm{C} 18$ column using isocratic elution. The mobile phase consisted of acetonitrile (A) and water buffered at $\mathrm{pH} 2.5$ with a concentrated orthophosphoric acid (B) in the volume ratio of 20:80(v/v), respectively. The detection was performed at $350 \mathrm{~nm}$. The method showed good intra-and inter-day precisions (RSD $<7.0 \%$ ), good accuracy (recovery for Doxycycline $>80 \%$ ) and high correlation coefficient $(r=0.998)$ for standards subjected to the entire procedure. The detection and quantification limits were $0.087 \mu \mathrm{g} / \mathrm{mL}$ and $0.264 \mu \mathrm{g} / \mathrm{mL}$.

\section{Experimental}

The content of doxycycline hyclate $100.0 \mathrm{mg} /$ tablet is $90.0-120.0 \mathrm{mg} /$ tablet. Determination of the content of doxycycline hyclate was carried out by the following procedure for external 
standard UV/Vis spectroscope under the operation conditions like wavelength as $276 \mathrm{~nm}$ and in this method purified water was used as solvent.

\section{Chemicals and solvents}

The reference sample of A-L Doxycycline $100 \mathrm{mg}$ capsules was obtained from the local market. Alcohol, water used was of HPLC grade and Whatman filter paper purchased from Merck Specialties Private Limited, Mumbai, India.

\section{Preparation of standard solution}

Accurately weighed $110 \mathrm{mg}$ of doxycycline hyclate standard transferred into a $100 \mathrm{~mL}$ amber volumetric flask and made up to volume with solvent, The first $5 \mathrm{~mL}$ of filtrate was discarded then filtered through Whatman paper No. $41.10 \mathrm{~mL}$ of this solution was diluted to $100 \mathrm{~mL}$ in a amber volumetric flask. $10 \mathrm{~mL}$ of this solution was further diluted to $100 \mathrm{~mL}$ with solvent.

\section{Preparation of sample solution}

Accurately weighed $330 \mathrm{mg}$ of the sample was taken (from 20 capsules) into a $100 \mathrm{~mL}$ amber volumetric flask. Dissolved it and diluted to volume with solvent. Filtered the sample through Whatman No.41, and discarded the first $5 \mathrm{~mL}$ of filtrate then diluted $10 \mathrm{~mL}$ of this solution to $100 \mathrm{~mL}$ in a volumetric flask with solvent. Further diluted $10 \mathrm{~mL}$ of this solution to $100 \mathrm{~mL}$ in a volumetric flask. Absorbance was measured for both standard and sample at $276 \mathrm{~nm}$ using $1 \mathrm{~cm}$ cell.

\section{Results and Discussion}

\section{Test validation procedure and requirements}

The analytical performance of the method of analysis was checked for specificity, accuracy, linearity and method precision.

\section{Specificity}

The specificity of the method can be determined with the addition of impurities and degradation products, obtained experimentally or by inducing their formation ${ }^{11}$. The tablets were subjected to degradation in acidic, alkaline, oxidative, watery and photolytic media. Decreases occurred in all absolute peak areas of doxycycline hyclate, confirming the qualitative specificity. These forced degradation studies show the susceptibility of the drug against degradation in acidic, basic, oxidative and photolytic media. This suggests that the method has specificity and can be used in stability studies.

\section{Linearity}

The linearity of an assay method is its ability to elicit test results, which are directly proportional to the concentrations of drug actives in samples in a given range. Proof of linearity justifies the use of single-point calibrations. The correlation coefficient of the regression line for doxycycline hyclate was found that 0.99 . Five solutions containing 50 , $75,100,125$ and $150 \%$ of doxycycline hyclate, relative to the working concentrations, were prepared and read according to the method of analysis. A linear regression curve was constructed, the correlation coefficient $\left(\mathrm{R}^{2}\right)$ and assessment value calculated. The correlation coefficient $\left(\mathrm{R}^{2}\right)$ for doxycycline hyclate is 1.00 . The plot is a straight line and the assessment value (z) is 3 for doxycycline hyclate. The results are tabulated in the Table 1 and Curve is shown in the Figure 2. 


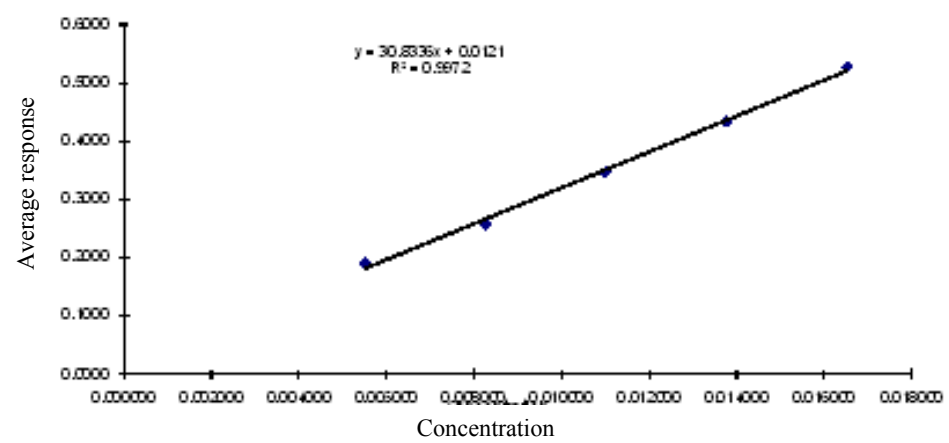

Figure 2. Linearity curve

Table 1. Linearity Results

\begin{tabular}{ccccc}
\hline $\begin{array}{c}\text { Sample } \\
\text { Number }\end{array}$ & Concentration & Response 1 & Response 2 & $\begin{array}{c}\text { Average } \\
\text { Response }\end{array}$ \\
\hline $50 \%$ & 0.005506 & 0.1906 & 0.1909 & 0.1908 \\
$75 \%$ & 0.008259 & 0.2584 & 0.2584 & 0.2584 \\
$100 \%$ & 0.011012 & 0.3474 & 0.3474 & 0.3474 \\
$125 \%$ & 0.013765 & 0.4344 & 0.4343 & 0.4344 \\
$150 \%$ & 0.016518 & 0.5272 & 0.5272 & 0.5272 \\
\hline
\end{tabular}

\section{Accuracy}

The accuracy of an analytical method expresses the closeness of test results obtained by that method to the true value. The percentage recovery of the active compounds, for each solution prepared were within the limit of actual amount. Sample solutions were spiked with known concentrations of doxycycline hyclate to result in concentrations representing 50, 75, 100, 125 and $150 \%$ of doxycycline hyclate relative to the working concentration. The absorbencies of the above samples were read in duplicate according to the method of analysis. From the accuracy results, the percentage recovery values for doxycycline hyclate satisfy the acceptance criteria for accuracy across the range of $50-150 \%$. Results are tabulated in the Table 2 .

Table 2. Accuracy results

\begin{tabular}{cccccc}
\hline Sample & $\begin{array}{c}\text { Theoretical } \\
\text { Amount, mg }\end{array}$ & Response & $\begin{array}{c}\text { Actual } \\
\text { amount, mg }\end{array}$ & $\begin{array}{c}\% \\
\text { Recovery }\end{array}$ & $\begin{array}{c}\text { Average \% } \\
\text { Recovery }\end{array}$ \\
\hline $50 \%$ & 55.75 & 0.2141 & 58.09 & 104.2 & 104.2 \\
$50 \%$ & & 0.2140 & 58.09 & 104.2 & \\
$75 \%$ & \multirow{2}{*}{3.63} & 0.3018 & 81.90 & 97.9 & 97.9 \\
$75 \%$ & & 0.3018 & 81.90 & 97.9 & \\
$100 \%$ & \multirow{2}{*}{111.50} & 0.4126 & 111.95 & 100.4 & 100.4 \\
$100 \%$ & & 0.4127 & 111.98 & 100.4 & \\
$125 \%$ & \multirow{2}{*}{139.38} & 0.5068 & 137.51 & 98.7 & 98.7 \\
$125 \%$ & & 0.5068 & 137.51 & 98.7 & \\
$150 \%$ & \multirow{2}{*}{167.25} & 0.5922 & 160.69 & 96.1 & \multirow{2}{*}{96.1} \\
$150 \%$ & & 0.5923 & 160.71 & 96.1 & \\
\hline
\end{tabular}

\section{Method precision}

The precision of an analytical procedure expresses the degree of agreement among individual test results when the method is applied to multiple sampling of a homogenous sample. 


\section{Repeatability}

This parameter determines the repeatability of assay results under the same operating conditions over a short period of time. The \% RSD due to doxycycline hyclate concentration for the six samples was found to be $2.0 \%$. Six separated sample preparations were analysed according to the method of analysis. The \% RSD due to doxycycline hyclate concentration for the assay meets the requirements. Results are tabulated in the Table 3.

Table 3. Repeatability Results

\begin{tabular}{cc}
\hline Sample number & Results, mg/tablet \\
\cline { 2 - 2 } & Doxycycline hyclate content \\
\hline 1 & 102.0 \\
2 & 101.5 \\
3 & 101.5 \\
4 & 102.8 \\
5 & 102.5 \\
6 & 102.0 \\
Mean & 102.1 \\
\% RSD & 0.5 \\
\hline
\end{tabular}

\section{Intermediate precision}

Intermediate precision of an analytical procedure expresses intra-laboratory variations of the repeatability test performed by a different analyst, on a different day, using different reagents and solvents. The \% RSD due to Doxycycline hyclate concentration for the six samples is found to be $2.0 \%$. The mean results obtained in the repeatability, and the intermediate precision differ by more than $3.0 \%$. Six separated sample preparations were analyzed according to the method of analysis. The \% RSD for intermediate precision is $1.3 \%$. The intermediate precision and repeatability comply as they differ by $0.6 \%$. Results are tabulated in the Table 4 and Table 5 respectively.

Table 4. \% Relative Standard Deviation (RSD)

\begin{tabular}{cc}
\hline Sample & Results (mg/capsule) \\
\cline { 2 - 2 } & Doxycycline hyclate \\
\hline 1 & 100.4 \\
2 & 102.8 \\
3 & 103.4 \\
4 & 104.1 \\
5 & 103.7 \\
6 & 103.3 \\
Mean & 103.0 \\
\% RSD & 1.3 \\
\hline
\end{tabular}

Table 5. Intermediate precision and repeatability

\begin{tabular}{cc}
\hline Sample & Mean Results (mg/capsule) \\
\cline { 2 - 2 } & Doxycycline hyclate \\
\hline Repeatability & 102.1 \\
Intermediate Precision & 103.0 \\
Mean & 102.6 \\
\% RSD & 0.6 \\
\hline
\end{tabular}




\section{Range}

Range of an analytical procedure is the interval between the upper and lower concentration of analyte in the sample for which it has been demonstrated that the analytical procedure has a suitable level of precision, accuracy and linearity. Based on the accuracy results, the range for the assay of A-L Doxycycline $100 \mathrm{mg}$ tablets is $50-150 \mathrm{mg} / \mathrm{capsule}$ of doxycycline hyclate, which represents 50 to $150 \%$ of the working concentration.

\section{Declaration on the validity of the method}

The method for the assay of A-L doxycycline $100 \mathrm{mg}$ tablets complies with the requirements for linearity, specificity, method precision and accuracy across the range of 50 to $150 \%$. The method is therefore acceptable as valid.

\section{References}

1. Sweet R L, Schachter J, Landers D V, Ohm-Smith M and Robbie M O, Am J Obstet Gynecol., 1988, 158(3 Pt 2), 736-741. PMID 3162653.

2. Gjønnaess H and Holten E, Acta Obstet Gynecol Scand., 1978, 57(2), 137-739; DOI:10.3109/00016347809155893 PMID 345730.

3. Määttä M, Kari O, Tervahartiala T, Sirje Peltonen, Marjatta Kari, Matti Saari and Timo Sorsa, Graefes Arch Clin Exp Ophthalmol., 2006, 244(8), 957-962; DOI:10.1007/s00417-005-0212-3 PMID 16411105.

4. Quarterman M J, Johnson D W, Abele D C, Lesher J L, Hull D S and Davis L S, Arch Dermatol., 1997, 133(1), 49-54; DOI:10.1001/archderm.1997.03890370055009 PMID 9006372.

5. Walker D H, Paddock C D and Dumler J S, Med Clin North Am., 2008, 92(6), 1345 1361; DOI:10.1016/j.mcna.2008.06.002 PMID 19061755.

6. Snežana S Mitić, Gordana Ž Miletić, Danijela A Kostić, Danielač Nasković-Đokić, Biljana B Arsić and Ivana D Rašić, J Serb Chem Soc., 2008, 73(6), 665-671; DOI:10.2298/JSC0806665M.

7. Ramesh J Pavagada, Basavaiah Kanakapura, Divya R Mysore, Rajendraprasad Nagaraju, Vinay B Kanakapura and Revanasiddappa D Hosakere, J Anal Chem., 2011, 66(5), 482-488; DOI:10.1134/S1061934811050157

8. Pavagada J Ramesh, Kanakapura Basavaiah, Kalsang Tharpa, Kanakapura Basavaiah Vinay and Hosakere Doddarevanna Revanasiddappa, J Pre-Clinical Clinical Res., 2010, 4(2), 101-107.

9. Ghada M Hadad, Alaa El-Gindy and Waleed M M Mahmoud, Spectrochim Acta Part A: Mole Biomole Spectr., 2008, 70(3), 655-663; DOI:10.1016/j.saa.2007.08.016.

10. Slavica M Sunarić, Marko S Denić, Zoran Ž Bojanić and Vladmila V Bojanić, $J$ Chromatogr B, 2013, 939(15), 17-22; DOI:10.1016/j.jchromb.2013.08.035.

11. Ermer J, J Pharm Biomed Anal., 2001, 24, 755-767. 